\title{
COVID 19 e a propagação de fake news sobre a contaminação pelo dióxido de carbono com o uso de máscaras faciais: Um estudo de reflexão
}

\author{
COVID 19 and the propagation of fake news on carbon dioxide contamination with the \\ use of facial masks: A reflection study
}

COVID 19 y la propagación de fake news sobre la contaminación por dióxido de carbono con el uso de máscaras faciales: Un estudio de reflexión

Recebido: 25/07/2021 | Revisado: 30/07/2021 | Aceito: 31/07/2021 | Publicado: 06/08/2021

\author{
Vera Lucia Freitag \\ ORCID: https://orcid.org/0000-0002-5897-7012 \\ Universidade de Cruz Alta. Brasil \\ E-mail: verafreitag@hotmail.com \\ Marcos Geraldo Dell'Antonio \\ ORCID: https://orcid.org/0000-0002-3938-6321 \\ Complexo de Ensino Superior de Santa Catarina, Brasil \\ E-mail: madellaqme@gmail.com
}

\begin{abstract}
Resumo
Objetivo: refletir sobre a propagação de fake news relacionado a contaminação pelo dióxido de carbono pelo uso de máscaras faciais em prevenção a COVID 19. Metodologia: estudo de abordagem qualitativa, exploratório e descritivo, do tipo estudo de reflexão, a partir de publicações sobre o tema e fake news sobre possíveis malefícios do uso de máscaras durante pandemia da COVID 19, a qual aflige o mundo atualmente. Ainda, busca de artigos e livros científicos. Resultados: os resultados mostraram que o uso de máscaras de qualquer natureza não tem relação à hipóxia pela suposta reabsorção do dióxido de carbono proveniente do metabolismo celular, mesmo em pessoas com comorbidades e submetidas a exercícios físicos. Conclusão: faz-se necessário que seja comprovada a eficácia do uso de máscaras, atentando para a conscientização social, desmistificando os fake news associadas à ciência, principalmente em relação a hipoxemia.
\end{abstract}

Palavras-chave: Máscaras Faciais; Coronavirus; Fake News; Dióxido de Carbono; Hipóxia.

\begin{abstract}
Objective: to reflect on the propagation of fake news related to carbon dioxide contamination by the use of face masks in prevention of COVID 19. Methodology: study with a qualitative, exploratory and descriptive approach, of a reflection study type, based on publications on the theme and fake news about possible harm caused by the use of masks during the COVID 19 pandemic, which currently afflicts the world. Also, search for scientific articles and books. Results: the results showed that the use of masks of any kind is not related to hypoxia due to the supposed reabsorption of carbon dioxide from cell metabolism, even in people with comorbidities and undergoing physical exercise. Conclusion: it is necessary to prove the effectiveness of the use of masks, paying attention to social awareness, demystifying the fake news associated with science, especially in relation to hypoxemia.
\end{abstract}

Keywords: Facial Masks; Coronavirus; Fake News; Carbon Dioxide; Hypoxia.

\section{Resumen}

Objetivo: reflexionar sobre la propagación de noticias falsas relacionadas con la contaminación por dióxido de carbono por el uso de mascarillas en la prevención de COVID 19. Metodología: estudio con enfoque cualitativo, exploratorio y descriptivo, de tipo estudio de reflexión, basado en publicaciones sobre la tema y fake news sobre los posibles daños causados por el uso de máscaras durante la pandemia de COVID 19, que actualmente aflige al mundo. Además, busque artículos y libros científicos. Resultados: los resultados mostraron que el uso de mascarillas de cualquier tipo no se relaciona con hipoxia por la supuesta reabsorción de dióxido de carbono del metabolismo celular, incluso en personas con comorbilidades y en ejercicio físico. Conclusión: es necesario demostrar la efectividad del uso de máscaras, prestando atención a la conciencia social, desmitificando las fake news asociadas a la ciencia, especialmente en relación a la hipoxemia.

Palabras clave: Máscaras Faciales; Coronavirus; Fake News; Dióxido de Carbono; Hipoxia. 


\section{Introdução}

A pandemia COVID 19 teve seu marco inicial em dezembro de 2019, na capital da província de Hubei, Waham, na China, o vírus Sars-Cov-2 (Severe Acute Respiratory Syndrome Coronavirus 2), uma variação de coronavírus humano foi identificado e tornou-se o novo desafio mundial, impactando o modo de vida da população nas mais diferentes perspectivas, mas de forma mais agressiva, nos campos de saúde e economia. A Covid-19 já infectou cerca de 193.165.622 no mundo e 19.632.443 pessoas em solo brasileiro, e vitimou cerca de 4.143.105 em todo o mundo, contabilizando 189 países, sendo 548.340 no Brasil (OMS, 2021).

Desde a descoberta e disseminação da Sars-Cov-19 pelo mundo, até o momento, uma série de medidas vem sendo adotadas, objetivando reduzir o contagio, a fim de que o número de infectados agravados não supere a capacidade dos sistemas de saúde. Entre as medidas, tem-se adotado o distanciamento social, testagem, quarentenas, uso de máscaras, adoção de higienização das mãos e superfícies, assim como evitar tocar o rosto. A alteração na forma de viver foi sentida e compartilhada por toda a população mundial; um grande sentimento de insegurança e medo propagou-se aumentando e reforçando problemas de saúde mental. Lockdowns, fechamento de comércio, restrição a reuniões presenciais e aglomerações mudaram rapidamente a rotina em diversos lugares (Anvisa, 2020; Aquino et al., 2020; Brasil, 2020b).

Neste contexto a utilização de máscara gerou polêmicas, onde vários fake news ${ }^{1}$ foram publicados na mídia, conhecida como a pseudociência que se alastra por diversas mídias sociais. Fake news como: máscaras sem qualidade distribuídas pelo Ministério da Saúde; Máscaras de doação da China são contaminadas com coronavírus; o uso prolongado causa hipóxia; intoxicação por gás carbônico (CO2); Organização Mundial da Saúde (OMS) e outros países não recomendam uso de máscara contra a Covid-19; deve-se trocar a máscara a cada 10 minutos; causa tontura, fadiga e desconforto; há quebra da glicose e geração de ácido láctico; máscara deixa sangue acido e causa coronavirus. Todas estas notícias falsas tem causado pânico na população, a qual vive e vivencia um momento pandêmico sem precedentes.

Contudo, neste estudo, deter-se-á a questão da hipoxemia pela inalação de gás carbônico, visto que a pessoa pode sentir desconforto, como calor ao usá-la e acreditar em tal possibilidade, e o risco de contágio pelo não uso da máscara pode ser falal no contexto da COVID 19. Em análise realizada por Nishioka (2020), menciona que é preocupante que o desconforto que pode ocorrer com o uso das máscaras equivocadamente atribuído a um suposto risco causado pelo $\mathrm{CO} 2$, o que pode desencorajar o emprego de uma medida que é comprovadamente efetiva sobre a transmissão do vírus, bem como de outras doenças de transmissão respiratória (Brasil, 2020).

Neste contexto, estudo que objetivou analisar se máscaras de tecido ou cirúrgicas prejudicam a oxigenação ou a ventilação em repouso ou durante a atividade física com 50 voluntários adultos (idade mediana de 33 anos; 32\% com comorbidade), os resultados mostraram que não houve episódios de hipoxemia ou hipercarbia (0\%; intervalo de confiança de 95\% 0-1,9\%). Em comparações emparelhadas, não houve diferenças estatisticamente significativas em $\mathrm{CO} 2$ ou $\mathrm{SpO} 2$ entre as medições basais sem máscara e aquelas com qualquer

${ }^{1}$ O Canal Saúde Sem Fake News do Ministério da Saúde, foi criado em agosto de 2018 com o intuito de desmentir notícias falsas que circulam na internet. Qualquer cidadão poderá enviar gratuitamente mensagens com imagens ou textos que tenha recebido nas redes sociais para confirmar se a informação procede, antes de continuar compartilhando. Atualmente o canal tem uma aba específica direcionando os usurários para notícias apenas sobre a Covid-19 podendo ser acessada através do site: https://www.saude.gov.br/fakenews/. 
tipo de máscara, tanto em repouso quanto após caminhada vigorosa por dez minutos. Assim, o risco de comprometimento patológico das trocas gasosas com máscaras de tecido e máscaras cirúrgicas é quase zero na população adulta em geral (Shein et al., 2021). Neste contexto, Shaw et al (2021), afirmam que as máscaras faciais podem ser usadas durante o exercício sem influência no desempenho e com impactos relativos às variáveis fisiológicas.

Faz-se necessário tais esclarecimentos, visto que a utilização de máscaras e demais cuidados de precauções a COVID 19, deverão ser mantidos por muito tempo, até que atinja-se a imunidade de rebanho. Sendo assim, este estudo objetivou refletir sobre a propagação de fake news relacionado a contaminação pelo dióxido de carbono pelo uso de máscaras faciais em prevenção a COVID 19.

\section{Metodologia}

Estudo de abordagem qualitativa, exploratório e descritivo, tipo estudo de reflexão, elaborado a partir de publicações consideradas fake news sobre possíveis malefícios do uso de máscaras durante pandemia da COVID 19 , a qual aflige o mundo atualmente.

Elencou-se a pesquisa qualitativa, pois ela empenha-se em mostrar uma série de significados que não podem ser quantificados, direcionando-se a percepção e interpretação das relações sociais. A pesquisa qualitativa tem um olhar mais subjetivo, por isso consegue transmitir valores, atitudes, crenças e sentimentos que buscam descrever fenômenos que não podem ser sintetizados em números (Minayo, 2015).

O método descritivo pretende investigar, registrar e analisar os acontecimentos, sem interferência do pesquisador, que deve procurar com total exatidão entender as variáveis e frequências das ocorrências (Triviños, 2009). Ainda, visa descrever as características de uma população. Incluem-se neste tipo de estudo as pesquisas que investigam opiniões, atitudes e crenças de uma população (Gil, 2017).

A pesquisa exploratória busca possibilitar aproximação a determinado assunto, assim é realizada uma busca ampla, com a finalidade de deixa-lo mais claro. Tem como propósito tornar o problema explícito, na medida em que se adquire maior familiaridade com ele. Para o planejamento desta fase da pesquisa é interessante considerar os mais variados aspectos relacionados ao fato ou fenômeno estudado (Gil, 2017).

A partir de artigos e livros científicos, os autores realizam análise critica e reflexiva acerca da temática em questão, comprovando que o uso de máscaras não traz malefícios à saúde, bem como sobre a necessidade de utilização da mesma durante a pandemia.

\section{Resultados e discussão}

Desde o início da pandemia, tem-se desenvolvido esforços a fim de controlar a contaminação pelo coronavirus, com o objetivo de normalizar as atividades rotineiras da população. Foi fundamental aprender com a situação emergencial e repensar estratégias de controle e prevenção, que possam intervir no dia a dia da população mundial e trazer estabilidade e diminuição da morbimortalidade (Selvati et al., 2020). Nesta premissa a maior preocupação concentra-se na propagação de gotículas.

O coronavírus pode ser espalhado por gotículas suspensas no ar quando pessoas infectadas conversam, tossem ou espirram. Essas gotículas podem ter sua formação diminuída pelo uso de máscaras não profissionais. 
Estas máscaras atuam como barreiras físicas, diminuindo a exposição e o risco de infecção para a população em geral (Anvisa, 2020).

Existe a necessidade de diferenciar gotículas expelidas pelo trato respiratório com aerossóis pela esternutação (espirro) e tosse, pois os tamanhos das partículas dispersas são muito diferente (em torno de 5 micrômetros no caso dos aerossóis eliminados pelas vias aéreas) porém a possibilidade de contaminação existe e não pode ser descartada em hipótese alguma.

Outros estudos encontraram a presença do RNA do SARS-CoV-2 em ambientes hospitalares onde os cuidados aos portadores sintomáticos COVID-19, mas onde não havia acontecido geração de aerossol. A carga de RNA detectada era extremamente baixa em largos volumes na análise de ar. Sabe-se que a detecção viral de RNA 1 pela técnica de RT PCR não necessariamente indica a presença de vírus viável, ou seja, capaz de infectar as células e a possível replicação (Lana et al., 2020; Souza Neto et al., 2020). .

Ainda, pode ocorrer a contaminação externa ao ambiente hospitalar. É notório e evidente os surtos em ambientes fechados e por conseguinte às várias aglomerações, portanto podem sugerir o contágio via aerossol concomitante com a transmissão goticular. Porém existe a possibilidade da contaminação ser unicamente pela geração de gotículas e talvez por contato com fômites, uma via possível, porém não é objetivo aqui, mas a efetividade das proteções faciais.

As máscaras quando confeccionadas segundo protocolos da OMS, ocorre à troca de gases, de modo que quando expiramos o ar atravessa essa barreira. Se isso não ocorresse não entraria oxigênio durante a inspiração. O objetivo da orientação do uso é de inibir a entrada do vírus (coronovírus), pois ocorre a filtração das partículas que possam estar contaminadas. Tais partículas são muito maiores que a molécula de $\mathrm{CO} 2$, por esta razão o ar ultrapassa a barreira, todavia, as partículas virais contaminadas não. Desta maneira, não há possibilidade de o CO2 acumular o espaço entre a máscara e o rosto, ainda, o ar pode sair pelas laterais, visto que máscara não é hermeticamente fechada (OMS, 2020).

Assim, compreende-se que as gotículas de aerossóis são grandes comparadas às moléculas de gás carbônico (CO2), como a máscara é permeável, não há possibilidade de reter o $\mathrm{CO} 2$. O que pode-se sentir é a sensação de calor, por estas sobre a face.

A construção das máscaras seguem rigorosos padrões de normas técnicas para estabelecer níveis altos de proteção, diferente de máscaras artesanais. Assim, é possível saber a eficácia de filtragem das mesmas. A PFF2 filtra pelo menos $94 \%$ das partículas de 0,3 mícron ( 1 micrômetro $10^{-6}$ metros) de diâmetro, as mais difíceis de se capturar. A capacidade de filtragem da N95 é 95\%. Embora a N95 seja o modelo mais buscado em pesquisas no Brasil, é a nomenclatura dos Estados Unidos. O padrão no Brasil e na Europa é a PFF2. Esses padrões de respiradores, embora não sejam idênticos, são equivalentes (Freitas et al., 2020). Quanto a informação falsa em relação a hipóxia esta seria gerada pela utilização de máscaras, onde o dióxido de carbono seria reabsorvido pelo organismo.

Quanto a informação falsa em relação a hipóxia eu seria gerada pela utilização de máscaras, onde o dióxido de carbono seria reabsorvido pelo organismo prejudicando o ciclo respiratório celular é no mínimo inescrupuloso, pois em termos dos diâmetros moleculares tanto ao $\mathrm{O}_{2}$ que possui em torno de $1.21 \times 10^{-10} \mathrm{~m}$ e o $\mathrm{CO}_{2} 3.00 \times 10^{-10} \mathrm{~m}$ comparando com o diâmetro de entrelaçamento das máscaras PFF2 é de $3.00 \times 10^{-6}$ ou seja 10 mil vezes a diferença entre a diametralidade filtrante em relação às trocas gasosa (Léonard, 1934). 
Nesta premissa, estudo que objetivou avaliar a possibilidade de ocorrência de anormalidades nas trocas gasosas com o uso de máscaras em indivíduos com e sem comprometimento da função pulmonar, concluiu que a troca gasosa não é significativamente afetada pelo uso de máscara, mesmo em indivíduos com comprometimento pulmonar grave, e o desconforto da máscara não foi atribuído à reinalação de $\mathrm{CO} 2$ e hipoxemia, mas sim a reações neurológicas (impulsos aferentes aumentados da área altamente termossensível do rosto coberta pela máscara ou do aumento da temperatura do ar inspirado) ou fenômenos psicológicos associados, como ansiedade, claustrofobia ou respostas afetivas à percepção de dificuldade em respirar (Samannan et al., 2021).

A Organização Pan-Americana da Saúde (OPAS) disponibilizou o novo guia da Organização Mundial da Saúde (OMS) sobre máscaras cirúrgicas e de tecido, reiterando que o uso de máscaras evita a transmissão do coronavírus e assim salva vidas. Estas devem ser usadas como parte de uma estratégia abrangente de medidas para suprimir a transmissão do vírus. Neste contexto, ressalta ainda, a importância de manter a distância física de no mínimo um metro, lavar as mãos, usar álcool gel 70\% e evitar tocar na máscara e rosto (OPAS, 2020).

Em relação ao uso de máscaras cirúrgicas as orientações da OPAS/ONU/ANVISA (2020a, 2020b), salientam que é indicado para todos os profissionais de saúde e pessoas com sintomas respiratórios, visto que as gotículas são liberadas a tossir e ou expirar. Ainda, por pessoas que dispensam cuidados a outros com sintomas respiratórios e também em locais que circulam pessoas que apresentem sintomas respiratórios. Tais máscaras devem ser substituídas por uma nova, assim que esta estiver úmida e não reutilizá-las. Ainda em casos específicos são recomendadas a N95 e a PFF2 ou equivalente. Em relação a máscara caseira, para ser eficiente como uma barreira física, precisa seguir algumas especificações na confecção, como, ser dupla face, ou seja, ter duas camadas de tecido, não compartilhar, higienizar corretamente e ser adequada as medidas corretas para cobrir boca e nariz (Brasil, 2020).

Neste contexto, constata-se a importância da utilização de máscaras de proteção, confeccionadas segundo os protocolos dos órgãos governamentais, oferecendo assim proteção contra a contaminação pela COVID 19. Ainda pelas constituições das máscaras não há possibilidade de ocorrer hipoxemia.

Considera-se a respiração uma das funções fisiológicas mais importantes a oferecer sustento a vida e a saúde. O corpo humano necessita de suprimento adequado e contínuo de oxigênio (O2) para que todos os órgãos e células funcionem adequadamente. A respiração também é um processo essencial para a remoção de subprodutos metabólicos, tais como o CO2. O déficit significativo agudo de $\mathrm{O} 2$ causa hipoxemia e níveis aumentados de $\mathrm{CO} 2$, hipercapnia, mesmo por alguns minutos, podem ser gravemente prejudiciais e letais, enquanto a hipoxemia crônica e hipercapnia causam deterioração da saúde, exacerbação das condições existentes, morbidade e até mesmo poderá levar a óbito (Kenney; Wilmore \& Costill, 2021).

Diante disso, observa-se que não há possibilidade de hipoxemia pelo uso da máscara, visto que este método foi aderido desde o início da pademia, e os estudos supracitados comprovam a importância do uso desta, sem prejuízos à saúde. Sendo assim, é fundamental que sejam incentivadas as precauções relacionadas a COVID 19, não somente a utilização de máscaras, bem como lavagem das mãos, distanciamento social e demais cuidados rotineiros enquanto perdurar a pandemia. 


\section{Considerações Finais}

A evidência concreta que as inúmeras informações falsas (fake news), emitidas pelas diversas redes sociais em relação à hipóxia pela suposta reabsorção do dióxido de carbono proveniente do metabolismo celular, relacionado ao ciclo respiratório e posteriormente eliminado pela expiração, no mínimo é uma má intensão inescrupuloso e criminosa por pessoas que desconhecemos as intenções ou por obviedade não é o objetivo da publicação, mas a simples desconstrução informativa/científica de afirmativas incompatíveis com dados científicos amplamente e exaustivamente difundidos aos meios de pesquisa, portanto não há argumentação, discussão e comprovações plausíveis de tais posições não criteriosas e pouco referendadas em artigos científicos recorrentes. Tal situação causal atinge parte abrangente de uma população muitas vezes, opostas à ciência, por vezes por não compreender a linguagem científica, e uma parte delas, a postura negacionista quanto à informação aceita aos meios científicos, portanto, o alerta à desinformação atuante, gera/gerou casos infeccionais por muitas pessoas desatentas ou de similaridade atitudinal.

Assim, este estudo traz contribuições importantes a profissionais das mais variadas áreas do conhecimento, bem como a população em geral, por constatar que inexiste a possibilidade de hipóxia pelo uso da máscara, até mesmo em pessoas com comorbidades e submetidas à exercícios físicos. Contudo sugere-se a realização de projetos de pesquisa, ensino e extensão que contemplem a temática.

Ainda, tal estudo envolve um alerta de segurança para a efetividade do uso de máscara com o objetivo da proteção dos usuários, seja individual e de comprovada ação comunitária. Uma sugestão que possa ser de alguma forma aplicada seria o estudo qualitativo comparativo da utilização das máscaras para os seres humanos já vacinados com a primeira e segunda doses, estudos separados e posteriormente comparados, visando estabelecer uma hipótese de proteção seja pelo imunizante e concomitante com as máscaras a fim de alertar a possibilidade de alta contaminação mesmo pela nova variante Delta ou outras possíveis, sugerindo assim às autoridades sanitárias e afins, a não abolição do uso das referidas proteções faciais.

\section{Referências}

Agência Nacional de Vigilância Sanitária. Anvisa. (2020a). Nota Técnica GVIMS/GGTES/ANVISA nº 04/2020. Orientações para serviços de saúde: medidas de prevenção e controle que devem ser adotadas durante a assistência aos casos suspeitos ou confirmados de infecção pelo novo coronavírus (SARS-CoV-2). https://www.gov.br/anvisa/pt-br/centraisdeconteudo/publicacoes/servicosdesaude/notas-tecnicas/notatecnica-gvims_ggtes_anvisa-04_2020-25-02-para-osite.pdf

Agência Nacional de Vigilância Sanitária. Anvisa. (2020b) Covid-19: tudo sobre máscaras faciais de proteção. https://www.gov.br/anvisa/ptbr/assuntos/noticias-anvisa/2020/covid-19-tudo-sobre-mascaras-faciais-de-protecao

Aquino, E. M., Silveira, I. H., Pescarini, J. M., Aquino, R., Souza-Filho, J. A. D., Rocha, A. D. S., \& Lima, R. T. D. R. S. (2020). Medidas de distanciamento social no controle da pandemia de COVID-19: potenciais impactos e desafios no Brasil. Ciência \& Saúde Coletiva, 25, 2423-2446.

Brasil (2020). Ministério da Saúde. Covid-19: tudo sobre máscaras faciais de proteção. https://www.gov.br/anvisa/pt-br/assuntos/noticiasanvisa/2020/covid-19-tudo-sobre-mascaras-faciais-de-protecao.

Brasil (2020a). Ministério da Saúde. Painel Coronavírus - DATASUS: Painel de casos de doença pelo coronavírus 2019 (COVID-19) no Brasil. v.2.0. Brasília - DF, 2020a. Disponível em: < https://covid.saude.gov.br/>.

Brasil, UNA-SUS (2020). O uso de máscara diminui os níveis de oxigênio e aumenta os de gás carbônico no sangue? Sérgio de Andrade Nishioka. Médico infectologista e Doutor em Epidemiologia. https://www.unasus.gov.br/especial/covid19/markdown/330.

Freitas, C. M. D., Barcellos, C., Villela, D. A. M., Matta, G. C., Reis, L. C., \& Portela, M. C. (2020). Boletim Observatório Covid-19 após 6 meses de pandemia no Brasil. 
Research, Society and Development, v. 10, n. 10, e104101018696, 2021 (CC BY 4.0) | ISSN 2525-3409 | DOI: http://dx.doi.org/10.33448/rsd-v10i10.18696

Gil, A. C. (2017). Como Elaborar Projetos de Pesquisa. (6ª . ed.). Atlas.

Kenney, W. L., Wilmore, J. H., Costill, D. L. (2012). Cinética Humana; Champaign, IL: 5ª ed. Fisiologia do esporte e exercício.

Lana, R. M., Coelho, F. C., Gomes, M. F. D. C., Cruz, O. G., Bastos, L. S., Villela, D. A. M., \& Codeço, C. T. (2020). Emergência do novo coronavírus (SARS-CoV-2) e o papel de uma vigilância nacional em saúde oportuna e efetiva. Cadernos de Saúde Pública, 36, e00019620.

Léonard B. L. (1934). The Kinetic Theory of Gases, second edition, Diameters of molecules. Mcgraw-Hill Book Company, Inc. New York ad London, Second Edition. 639 p.

Minayo, M. C. D. S. (2015). O desafio do conhecimento. (14 ${ }^{\mathrm{a}}$ ed.). Hucitec.

Organização Mundial da Saúde (OMS) (2020). COVID-19. Dashboard by the Center for Systems Science and Engineering (CSSE) at Johns Hopkins University (JHU). https://gisanddata.maps.arcgis.com/apps/dashboards/bda7594740fd40299423467b48e9ecf6.

Organização Panameriacana de Saúde (OPAS) (2020). Orientação sobre o uso de máscaras no contexto da COVID-19. https://iris.paho.org/bitstream/handle/10665.2/52254/OPASWBRACOVID-1920071_por.pdf?sequence=1\&isAllowed=y .

Samannan, R., Holt, G., Calderon-Candelario, R., Mirsaeidi, M., \& Campos, M. (2021). Effect of face masks on gas exchange in healthy persons and patients with chronic obstructive pulmonary disease. Annals of the American Thoracic Society, 18(3), $541-544$.

Selvati, F. S., Teixeira, L. G. F., Loureiro, L. H., Pereira, R. M. S. (2020). Estratégias de controle da covid-19 no Brasil: o que a pandemia nos ensina? Research, Society and Development, 9 (8), e664986293-e664986293.

Shaw, K., Zello, G. A., Butcher, S., Ko, J., Bertrand, L., \& Chilibeck, P. D. (2021). The Impact of Face Masks on Performance and Physiological Outcomes during Exercise: A Systematic Review and Meta-analysis. Applied Physiology, Nutrition, and Metabolism, 46(7):693-703

Shein, S. L., Whitticar, S., Mascho, K. K., Pace, E., Speicher, R., \& Deakins, K. (2021). The effects of wearing facemasks on oxygenation and ventilation at rest and during physical activity. Plos one, 16(2), e0247414.

Sousa Neto, A. R., Bortoluzzi, B. B., \& de Freitas, D. R. J. (2020). Equipamentos de proteção individual para prevenção de infecção por SARS-COV-2. JMPHC. Journal of Management \& Primary Health Car.| ISSN 2179-6750, 12, 1-7.

Triviños, A. N. S. (2009). Introdução à pesquisa em ciências sociais: a pesquisa qualitativa em educação. São Paulo: Atlas, 1987. Outros números do Informe Rural ETENE: ANO, 3, 25. 